\title{
Strategies to Alleviate the Incidence of Ascites in Broilers: a Review
}

E Author(s)

Aftab $U^{1}$

Khan $\mathrm{AA}^{+}$

Khushal Feed and Farms (pvt) Ltd, Islamabad, Pakistan

+Department of Microbiology and Molecular Genetics

Punjab University, Lahore, Pakistan

\section{ABSTRACT}

Ascites is a complex problem caused by many interacting factors such as genetics, environment and management. Many nutritional, medicinal and management strategies have been proposed to alleviate the problem. Higher levels of dietary vitamin $\mathrm{C}$ and $\mathrm{E}$ along with selenium yeast might be beneficial, presumably because of their role in improving cellular integrity. Oils rich in n-3 fatty acids have been shown to reduce pulmonary hypertension and, consequently, ascites incidence. The potential use of flax oil has already been demonstrated, whereas the effects of other oils rich in n-3 fatty acids (fish, linseed and canola oils) remain to be investigated. The assessment of the effects of dietary electrolyte balance on ascites incidence seems to be a promising field of research in broiler nutrition. In general, reducing the dietary level of salt $(\mathrm{NaCl})$ and adding bicarbonates to the diet and drinking water have been proposed as potential "cost-effective" methods to reduce ascites incidence. The use of nutrients/drug agents that increase the vascular capacity of the lungs or decrease the pulmonary vascular resistance may help to alleviate the problem, but economic and local feed regulations might restrict such use. Diuretics have also shown positive effects, presumably because there is a reduction of sodium and fluid retention in the body; litter humidity however must be closely monitored if diuretics are continuously administered. As the high metabolic rate (fast growth) is a major factor contributing to the susceptibility of broilers to ascites, early-age feed or nutrient restriction (qualitative or quantitative) or light restriction in order to slow down the growth rate seem practically viable methods, since final body weight is not compromised. Optimization of the house temperature and ventilation in cold weather seem helpful practices to decrease ascites incidence. Under practical conditions, it might be interesting to test the additive effects of different approaches when used in combination.

\section{INTRODUCTION}

Pulmonary Hypertension Syndrome (PHS or ascites) is one of the major causes of mortality and morbidity in modern broiler production. Genetics, environment, and management all seem to interact to produce a cascade of events that culminate in ascites syndrome. It is generally proposed that the high metabolic rate of current broiler lines causes an increased demand for oxygen, especially in cold environments or when birds are fed high nutrient density diets. In such situations, the proportionately underdeveloped cardio-respiratory system of modern broilers fails to fulfill the required oxygen demand, resulting in hypoxemia. High hematocrit levels and vasoconstriction are consequences of hypoxemia that lead to elevated viscosity/pressure and low oxygen saturation of blood. Therefore, the heart (right ventricle) must respond 
with more vigorous contractions in order to overcome the oxygen insufficiency and to cope with the high venous return, resulting in the development of pulmonary hypertension and congestive heart failure.

Based on the published literature, this revision aims to present some specific and general recommendations that have been shown to alleviate the incidence of ascites in broilers. The information presented herein may hopefully provide some practical guidelines to veterinarians and anyone involved in poultry production that face this challenge in field conditions.

\section{NUTRITIONAL CONTROL}

Manipulation of the levels of different nutrients in the diets has been and still is an important research area in broiler nutrition, since it affects the incidence of ascites. Based on the proposition that lipid peroxidation may be involved in the degeneration of cardiac tissue and lead to the development of pulmonary hypertension syndrome, the possible role of nutrients with "antioxidant" properties has been investigated in many studies. The combined use of higher dietary levels of vitamin E and organic selenium (250 IU vitamin $E$ and $0.3 \mathrm{ppm}$ selenium yeast) significantly reduced the mortality caused by PHS and improved gain: feed in cold-stressed broilers (Roch et al., 2000). Such better results have been attributed to improved cellular integrity provided by the antioxidant effects of vitamin $E$ and selenium. Selenium yeast added to diets $(0.1 \%)$ has also been shown to reduce ascites mortality from $11 \%$ (no selenium yeast) to $2.3 \%$ (with selenium yeast) with a concurrent increase in body weight gain (14\%) in supplemented broilers compared to the non-supplemented birds (Stanley et al., 1998). Supplementation of $500 \mathrm{mg}$ Vitamin C per kg diet has reduced the number of thick-walled peripheral vessels in the lungs and ascites incidence (Xiang et al., 2002).
Nevertheless, Packed Cell Volume, weight gain and feed efficiency were not affected by the treatment (Table 1). In addition to the suggestions that vitamin C may exert positive effects on alleviating ascites because it depresses the oxygen-derived free radical status (Ladmakhi et al., 1997), the results presented in Table 1 show that vitamin $C$ markedly reduced the muscularization of the pulmonary arterioles as indicated by the lower number of thick-walled peripheral vessels (TWPV). Thus, it may reduce the resistance to blood flow that is seen in pulmonary vessels of broilers.

The administration of flax oil (50 g per $\mathrm{kg}$ diet) to broilers under hypobaric conditions reduced right ventricular hypertrophy, hematocrit and hemoglobin content; erythrocyte deformability was increased and whole blood viscosity was reduced (Walton et al. 1999) (Table 2). Diets containing flax oil (50 g oil per $\mathrm{kg}$ ) increased the content of unsaturated fatty acids in erythrocyte membranes, thereby increasing the fluidity of the membranes and the deformability of erythrocytes (lower filtration index; Table 2). Flax oil is rich in alpha-linolenic acid, which is a precursor of eicosapentaenoic acid (EPA, 20:5 n-3) and docosahexaenoic acid (DHA, 22:6 n-3). As EPA and DHA might be further metabolized to prostacyclins, $\mathrm{PGI}_{3}$ and $\mathrm{PGI}_{2}$, which function as coronary relaxants, it was suggested that the higher dietary ratio of $n 3 /$ $\mathrm{n} 6$ fatty acids increase the production of compounds that reduce the resistance to blood flow (Walton et al., 1999). A later study evaluated the effect of dietary flax oil and antioxidants on the incidence of ascites in broilers reared under low temperatures. Although the results were statistically non-significant, the group supplemented with flax oil at $50 \mathrm{~g}$ per $\mathrm{kg}$ of diet tended to show lower incidence of ascites and decreased right ventricle to total ventricle ratio compared to broilers given control diets (Walton et al., 2001).

\begin{tabular}{|c|c|c|c|c|c|}
\hline Treatment & Gain, $\mathbf{g}$ & Feed conversion, g/g & Incidence of ascites, \% & RV/TV ${ }^{B}$ & TWPV', \% \\
\hline Normal Control & $423^{a}$ & $3.06^{a}$ & $2.0^{\mathrm{a}}$ & 0.34 & $11.57^{a}$ \\
\hline Cold Control & $372^{b}$ & $3.64^{b}$ & $11.43^{b}$ & 0.33 & $18.36^{c}$ \\
\hline Cold + $500 \mathrm{mg}$ & & & & & \\
\hline Vit. C per kg feed & $386^{b}$ & $3.42^{b}$ & $1.42^{\mathrm{a}}$ & 0.31 & $13.79^{b}$ \\
\hline
\end{tabular}

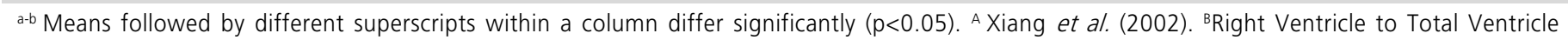
ratio (RV/TV). 'Thick-Walled Peripheral Vessels (TWPV).

\begin{tabular}{|c|c|c|c|c|c|}
\hline Treatment & Gain, $\mathbf{g}$ & RV/TV & Hemoglobin, g/l & Blood viscosity,Cps & Filtration Index, s \\
\hline AN blend $50 \mathrm{~g}$ per $\mathrm{kg}$ feed & 558 & $0.331^{\mathrm{a}}$ & $110^{\mathrm{a}}$ & $3.1^{\mathrm{a}}$ & $23.5^{a}$ \\
\hline Flax oil $50 \mathrm{~g}$ perkg feed & 542 & $0.305^{b}$ & $94.3^{b}$ & $2.8^{b}$ & $16.3^{b}$ \\
\hline
\end{tabular}

a-b Means followed by different superscripts within a column differ significantly $(p<0.05)$. A Walton et al. (1999) 
There are evidences that the inclusion of $1000 \mathrm{mg}$ potassium carbonate per liter of drinking water may be a practical method to increase blood oxygenation $\left(\mathrm{PaO}_{2}\right)$ of broilers and perhaps to act as a prophylactic to reduce losses due to ascites (Shlosberg et al., 1998). Similarly, birds fed on high-bicarbonate, low-chloride diets have shown significantly lower pulmonary hypertension and lower heart weights, and this technique has been suggested as a potential means to reduce pulmonary hypertension and ascites in broilers (Squires \& Julian, 2001). The addition of $1 \%$ sodium bicarbonate to the diets of broilers has decreased mortality due to ascites. The decrease was ascribed to the alkaline nature of sodium bicarbonate and a possible induction of alkalosis (Owen et al. 1994). It is generally proposed that treatments that potentially induce alkalosis may reduce the incidence of ascites, whereas treatments with acid-inducing effects may exacerbate it.

It has been shown that $1 \%$ L-arginine supplemented to the diet significantly reduced the right ventricle: total ventricle ratio and total ascites mortality (Wideman et al., 1995). It was proposed that L-arginine is required as a substrate for nitric oxide, a potent endogenous pulmonary vasodilator, when added at levels higher than the requirements for maximal growth.

\section{MEDICINAL CONTROL}

Pulmonary vasoconstriction and increased blood viscosity are the major effectors that ultimately lead to pulmonary hypertension and ascites. In this context, factors that tend to increase the vascular capacity of the lungs or decrease the pulmonary vascular resistance would theoretically reduce the incidence of ascites. To test this hypothesis, a number of drug agents have been studied. Researchers of the University of Guelph studied the effects of Diaoxinxuekang (a Chinese medicine) on ascites in broilers (Wang \& Hacker, 1993). Diaoxinxuekang has been reported to improve blood circulation. Besides, it is claimed to decrease oxygen consumption by cardiac myofibrils and improve the hydraulic pressure of blood in the heart. Diaoxinxuekang was added to experimental diets at $0,500,1500$, and $3500 \mathrm{mg}$ per $\mathrm{kg}$ and it was concluded that 3500 mg Diaoxinxuekang per $\mathrm{kg}$ of diet reduced the incidence of ascites in broilers, with no negative effects on the gain or feed efficiency.

Similarly, the addition of $0.2 \%$ of Aspirin to the diet has reduced the incidence of ascites (Balog et al., 2000a). Aspirin addition, however, has also resulted in significant reduction in the final body weight of broilers when compared to the control group (no aspirin in the diet). Since it is suggested that the lower body weight also reduces the intensity of ascites in broilers, it was not clear whether the reduction in ascites incidence was a direct effect of aspirin, or an indirect effect of the lower body weight (Acar et al., 1995; Balog et al., 2000b).

Researchers of the University of Arkansas have studied the effect of a diuretic named Furosemide on the incidence of ascites. The addition of $0.015 \%$ Furosemide to the diet has reduced both the right: total ventricle ratio and the cumulative ascites mortality. Body weight, however, has been significantly reduced as a result of this treatment in one of the two experiments reported (Wideman et al., 1995). Lower levels of Furosemide $(0.01 \%$ of diet) have significantly reduced ascites mortality but had no effect on body weight. It was later suggested that dietary furosemide added at levels of $0.015 \%$ does not seem to influence pulmonary vessels in broilers but it may extend the survival time of broilers during the pathophysiological progression of PHS (Forman \& Wideman, 2001).

The supplementation of feed with $0.25 \mathrm{ppm}$ Clenbuterol, a beta-adrenergic agonist, has been shown to reduce ascites mortality in broilers (Ocampo et al., 1998). Dietary supplementation with Atenolol, a beta-adrenergic blocker, has also been shown to numerically reduce ascites incidence in broilers (7\%) when compared with the non-supplemented diet (15\%) (Hassanzadeh et al., 2002). Further studies, however, are required to elucidate the precise mechanism by which these drugs reduce the incidence of pulmonary hypertension and ascites.

Chinese researchers studied the effect of dietary supplementation with Coenzyme Q10 (CoQ10) on the performance and ascites parameters of broilers (Geng et al., 2004). CoQ10 supplemented at 20 or 40 mg per $\mathrm{kg}$ of diet resulted in significant reduction $(p<0.05)$ in ascites mortality compared to the negative control. Supplementation at $40 \mathrm{mg}$ per $\mathrm{kg}$ of diet also reduced $(p<0.05)$ the right ventricle to total ventricle ratio, Erythrocyte Osmotic Fragility and Pulmonary Arterial Diastolic Pressure when compared to the negative control. Besides, gain and feed efficiency tended to improve with increasing dietary levels of CoQ10 (Table 3). It was proposed that CoQ10 alleviate ascites by protecting the cell membrane and cell structure against peroxidants. 


\begin{tabular}{|c|c|c|c|c|c|c|}
\hline CoQ10, mg/kg & Gain, g & $F C R, g / g$ & AscitesMortality, \% & EOF, \% & PADP, $(\mathrm{kPa})^{c}$ & RV/TV \\
\hline 0 & 2.07 & 1.94 & $26.7^{a}$ & $30.1^{\mathrm{a}}$ & $3.11^{\mathrm{a}}$ & $0.39^{a}$ \\
\hline 20 & 2.13 & 1.85 & $5.0^{b}$ & $27.2^{\mathrm{b}}$ & $1.27^{\mathrm{b}}$ & $0.32^{b}$ \\
\hline 40 & 2.29 & 1.82 & $5.0^{\mathrm{b}}$ & $25.4^{\mathrm{b}}$ & $1.13^{\mathrm{b}}$ & $0.31^{b}$ \\
\hline
\end{tabular}

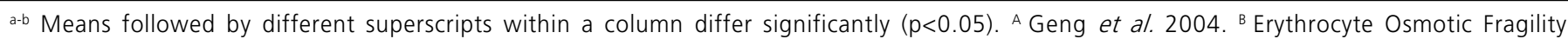

c Pulmonary Arterial Diastolic Pressure.

\section{FEED RESTRICTION PROGRAMS}

The growth rate or body weight gain in broilers has been shown to positively correlate with incidence of ascites. Broilers genetically selected for fast muscle growth seem more susceptible to ascites compared with slow-growing strains. Manipulation of the early growth cycle of broilers, with a subsequent compensatory gain, seems a practical and viable method to minimize losses caused by ascites. In this context, various feed restriction programs have been tested. Acar et al. (1995) studied the effect of earlyage feed restriction on the subsequent growth and the incidence of ascites in broilers. A feed restriction regimen was used from either 4-11 (FR1) or 7-14 (FR2) days of age, consisting of limiting daily intake of the birds to $75 \%$ of the ME required for normal growth. It was concluded that although ascites mortality could be significantly reduced in early feed-restricted birds, there was a decrease in body weight and breast meat yield in restricted vs. full-fed birds (Table 4). Balog et al. (2000b) studied the effect of different feed restriction regimens on the growth and ascites mortality in broilers. The following treatments were used: 1) fullfed control; 2) feed available for $8 \mathrm{~h} / \mathrm{d}$ for 6 weeks; 3) feed available for $8 \mathrm{~h} / \mathrm{d}$ for the first 3 weeks and then full-fed; 4) full-fed in the $1^{\text {st }}$ week, $8 \mathrm{~h} / \mathrm{d}$ for 3 weeks and full-fed for the remaining 2 weeks. Mortality due to ascites was significantly lower in all restricted groups, while weight gain at 42 days was significantly smaller only in group 2 in comparison to the full-fed group (control). Breast meat yield, however, was significantly low in all feed-restricted groups compared with the control. More recently, Camacho-Fernandez et al. (2002) studied the effect of different feeding programs on the incidence of ascites and the production parameter of male and female broilers. They concluded that the birds fed on an ad libitum low-nutrient density regimen $(2900 \mathrm{kcal}, 21 \% \mathrm{CP}$ for $0-21 \mathrm{~d} ; 3000 \mathrm{kcal}$, $19 \%$ CP for $22-35 \mathrm{~d}$; and $3160 \mathrm{kcal}, 17.5 \%$ CP for $36-$ $52 \mathrm{~d})$ showed significantly reduced $(p<0.0001)$ ascites mortality compared with the birds fed ad libitum with a high-nutrient density regimen $(3000 \mathrm{kcal}, 23.5 \% \mathrm{CP}$ for $0-21 \mathrm{~d} ; 3200 \mathrm{kcal}, 20.5 \%$ CP for 22-35 d; and 3300 $\mathrm{kcal}, 18.5 \%$ CP for $36-52 \mathrm{~d}$ ). In the study, body weight gain, feed efficiency, breast yield and abdominal fat yield were similar among treatments (Table 4). These results indicate that feed restriction programs might be potentially used to reduce the incidence of ascites; however, such programs must be carefully evaluated under different production systems.

\section{HUSBANDRY/MANAGEMENT}

Lower ambient temperatures trigger the incidence of ascites in broilers. The control of house temperature (particularly during brooding) could be extremely helpful in reducing ascites incidence. Lower brooding temperatures $\left(26.7 \mathrm{C}, 24.4 \mathrm{C}\right.$ and $21.1 \mathrm{C}$ in the $1^{\text {st }}, 2^{\text {nd }}$ and $3^{\text {rd }}$ weeks, respectively) have been shown to significantly increase ascites mortality at 6 weeks of age, when compared with higher brooding temperatures (Deaton et al., 1996). Therefore, minimum temperatures of $29.4 C, 26.7 C$ and $24.4 C$ in

\begin{tabular}{|c|c|c|c|c|c|}
\hline Treatment & Gain, $\mathbf{g}$ & Feed conversion, $\mathrm{g} / \mathrm{g}$ & Breast yield ${ }^{B}, \%$ & Ascites, \% & Pre-ascites, \% \\
\hline \multicolumn{6}{|l|}{ Acar et al. (1995) } \\
\hline Ad-lib Control & $822^{a}$ & 1.82 & $11.1^{\mathrm{a}}$ & $12.92^{\mathrm{a}}$ & 45.83 \\
\hline FR $1 \mathrm{~A}$ & $725^{b}$ & 1.77 & $10.57^{\mathrm{ab}}$ & $0.98^{\mathrm{b}}$ & 34.51 \\
\hline FR 2 A & $721^{\mathrm{b}}$ & 1.68 & $10.18^{b}$ & $5.55^{\mathrm{ab}}$ & 27.96 \\
\hline \multicolumn{6}{|c|}{ Camacho-Fernandez et al. (2002) } \\
\hline Control & 2616 & 2.30 & 32.95 & $3.82^{\mathrm{a}}$ & - \\
\hline Ad-lib low-density Diet A & 2607 & 2.34 & 32.25 & $1.36^{\mathrm{b}}$ & - \\
\hline
\end{tabular}


the first, second and third week, respectively, have been suggested to optimize the energetic efficiency of the ingested fuel while reducing ascites-related mortality to a minimum (Deaton et al., 1996). The general pathophysiology of the syndrome indicates that proper ventilation/air quality (provision of fresh-air with $\mathrm{O}_{2}$ and reduction in the levels of $\mathrm{CO}_{2}$ and $\mathrm{NH}_{3}$ in the poultry house) may be beneficial to attenuate the problem. Poor air quality in the house (such as high levels of dust and ammonia) has been shown to exert an oxidative stress on the antioxidants of the lining fluid in the lung of broilers and this was found to be positively correlated with the right ventricle to total ventricle ratio. Therefore, oxidative stress in the lung lining fluid may be related to subsequent development of ascites (Bottje et al., 1998). However, the economics of such inputs, i.e., brooding temperatures and ventilation rates, must be evaluated under different production systems to assess the commercial feasibility of using these as a tool to reduce ascites.

The effects of different lighting schedules on ascites have also been investigated. Broilers were kept on different lighting schedules, i.e., group 1 (23L:1D); group 2 (1L:3D, repeated six times a day); and group 3 (6L:18D for 14 days; 10L:14D between 15-21 days of age; 14L:10D between 22-28 d; 18L:6D between 29-35 d; and 23L:1D between 36-42 d). Birds kept on restricted lighting program (group 2 and 3) showed lower hematocrit and plasma T3 levels, and a numerically lower mortality due to ascites compared to the nonrestricted group (Hassanzadeh et al., 2003).

\section{REFERENCES}

Acar N, Sizemore FG, Leach GR, Wideman Jr. RF, Owen RL, Barbato GF. Growth of broiler chickens in response to feed restriction regimens to reduce ascites. Poultry Science 1995; 74:833-843.

Balog JM, Huff GR, Rath NC, Huff WE. Effect of dietary aspirin on ascites in broilers raised in hypobaric chamber. Poultry Science 2000a; 79:1101-1105.

Balog JM, Anthony NB, Cooper MA, Kidd BD, Huff GR, Huff WE, Rath NC. ascites syndrome and related pathologies in feed restricted broilers raised in a hypobaric chamber. Poultry Science 2000b; 79 : 318-323.

Bottje WG, Wang S, Kelly FJ, Dunster C, Williams A, Mudway I. Antioxidant defense in lung lining fluid of broilers: Impact of poor ventilation conditions. Poultry Science 1998; 77:516-522.

Camacho-Fernandez D, Lopez C, Avila E, Arce J. Evaluation of different dietary treatments to reduce the ascites Syndrome and their effect on corporal characteristics in broiler chickens. Journal of Applied Poultry Research 2002; 11:164-174.
Deaton JW, Branton SL, Simmons JD, Lott BD. The effect of brooding temperature on broiler performance. Poultry Science 1996; 75: 1217-1220.

Forman MF, Wideman Jr. RF. Furosemide does not facilitate vasodilation in broilers during chronic or acute unilateral pulmonary arterial occlusion. Poultry Science 2001; 80:937-943.

Geng AL, Guo YM, Yang Y. Reduction of ascites mortality in broilers by Coenzyme Q10. Poultry Science 2004; 83:1587-1593.

Hassanzadeh M, Buys J, Decuypere E. Further evidence for the involvement of the cardiac $\mathrm{I}^{2}$ adrenergic receptors in right ventricle hypertrophy and ascites in broiler chickens. Avian Pathology 2002: 31:177-181

Hassanzadeh M, Bozorgmehri Fard MH, Buys J, Decuypere E. Beneficial effects of alternative lighting schedule on the incidence of ascites and on metabolic parameters of broiler chickens. Acta Veterinaria Hungaria 2003; 51:513-520.

Ladmakhi MH, Buys N, Dewil E, Rahimi G, Decuypere E. The prophylactic effect of vitamin $C$ supplementation on broiler ascites incidence and plasma thyroid hormone concentration. Avian Pathology 1997; 26:33-44.

Ocampo L, Cortez U, Sumano H, Avial E. Use of low doses of Clenbuterol to reduce the incidence of ascites syndrome in broilers. Poultry Science 1998; 77:1297-1299.

Owen RL, Wideman RF, Leech RM, Cowen BS, Dunn PA, Ford BC Effect of age of exposure and dietary acidification or alkalization on mortality due to broiler pulmonary hypertension syndrome. Journal of Applied Poultry Research 1994; 3:244-252.

Roch G, Boulianne M, De Roth L. Effect of vitamin E and selenium on incidence of ascites, growth performance and blood parameters in cold-stressed broilers. Poultry Science 2000; 79 Suppl. 1:41.

Shlosberg A, Bellaiche M, Berman E, Ben David A, Deeb N, Cahaner A. Comparative effects of added sodium chloride, ammonium chloride, or potassium bicarbonate in drinking water of broilers, and feed restriction, on the development of the ascites syndrome. Poultry Science 1998; 77: 287-1296.

Squires EJ, Julian RJ. The Effect of dietary chloride and bicarbonate on blood $\mathrm{pH}$, hematological variables, pulmonary hypertension and ascites in broiler chickens. British Poultry Science 2001; 42: 207-212.

Stanley VG, Gray C, Krueger WF. Dual-effects of selenium-yeast on ascites and aflatoxicosis reduction in broiler chickens. Poultry Science 1998; 77 (Suppl. 1):2.

Walton JP, Bond JM, Julian RJ, Squires EJ. Effect of dietary flax oil and hypobaric hypoxia on pulmonary hypertension and hematological variables in broiler chickens. British Poultry Science 1999; 40:385-391.

Walton JP, Julian RJ, Squires EJ. The effect of dietary flax oil and antioxidant on ascites and pulmonary hypertension in broilers using a low temperature model. British Poultry Science 2001; 42:123-129. 
Wang JY, Hacker RR. Effects of Diaoxinxuekang on ascites in broilers. Poultry Science 1993; 72:1467-1472.

Wideman Jr. RF, Ismail M, Kirby YK, Bottje WG, Moore RW, Vardeman RC. Furosemide reduced the incidence of pulmonary hypertension syndrome (ascites) in broilers exposed cool environmental temperatures. Poultry Science 1995; 74:314-322.

Wideman Jr. RF, Kirby YK, Ismail M, Bottje WG, Moore RW, Vardeman RC. Supplemental L-arginine attenuates pulmonary hypertension syndrome (ascites) in broilers. Poultry Science 1995; 74:323-330.

Xiang RP, Sun WD, Wang JY, Wang XL. Effect of vitamin C on pulmonary hypertension and muscularization of pulmonary arterioles in broiler. British Poultry Science 2002; 43:705-712. 